\title{
Routine Follow up Care among Elderly Patients Suffering from Chronic Diseases at Assiut University Hospital Clinics
}

\author{
Ragab , A., G; Ebrahime , H., D \& Sharkawy , S., A. \\ Geriatric Nursing -Faculty of Nursing-Assiut University \\ Community Health Nursing-Faculty of Nursing-Assiut University
}

\begin{abstract}
:
Older adults increasingly experience chronic and debilitating illnesses and disabilities. Many illnesses and disabilities require long term care support manage chronic illness, maintain function, and investigate daily living (White, et al., 2012). The present study aimed at identifying the factors affecting follow up among elderly patient suffering from chronic diseases attending to the medical outpatient clinics at Assiut University Hospital. Subject \& methods: The present study carried out in six months started from October 2011 to April 2012. The sample consisted of 1179 elderly patient suffering from chronic disease. Structured Interview Questionnaire was developed by the researchers to collect the relative data, it consists of three parts. Part I: Included items related to socio demographic characteristic of the elderly patient. Part II: Included items related to chronic illnesses and family history. Part III: - Included investigations, frequency and place of follow up care. The main results of the present study showed that most of the elderly patient attending to outpatient clinic (84.1\%) their age ranged from $60-70$ years old, and more than half of them (53.4\%) were females, (77.8\%) of the sample were married, and (81.4\%) of them were illiterate, $(64.9 \%)$ lived in rural area. The present study clear that about one third of elderly patient $(32.7 \%)$ complain from chest disease, only $(0.8 \%)$ patients complain from hepatitis disease, and $(92.4 \%)$ of the elderly received their follow up care at University Hospital due to the health services and the low cost medications. Concerning the causes that preventing follow up: $(53.3 \%)$ said due to the financial causes, $(27.1 \%)$ at elderly depend on other member of the family and there are not available. Conclusion \& Recommendation: The results obtained from this study revealed that the ability of older adults to access health care was negatively due to family income, disability and transportation. In the light of the results, the follow recommendations suggested: Health insurance must be available for all elderly people over 60 years old who live in rural and urban area. Elderly people and their family should be acquainted with different services available in the community to help elderly to meet their needs.
\end{abstract}

\section{Key words: Elderly Patient - Chronic Diseases - Routine Follow Up.}

\section{Introduction:}

Older adults are generally defined as individuals ageing from 65 years old and above. Aging of the population is the most important demographic change observed in most countries worldwide. It is a phenomenon that was initially observed in the developed world, but more recently developing countries have shown the highest rates of increase (Eliopoulos, 2010).

Seniors World Chronicle's, (2007) Reported that 5 million senior citizens live in Egypt and this number is expected to increase to 13 million by the year 2030, according to an official report. By the year 2025, five of 10 nations in the world with the highest numbers of older adults will be developing countries, including Brazil, with an estimated 31.3 million people aged 60 year old or above.

Chronic diseases are diseases of long duration and generally slow progression. Chronic diseases include heart disease, stroke, cancer, chronic respiratory diseases and diabetes (WHO, 2011). In Egypt most of both males and females old adult

suffer from chronic diseases, the most common chronic disease in Egypt is cardiovascular diseases.
Male old adult cardiovascular diseases reach to $39 \%$ from all chronic diseases and about $42 \%$ from all female old adult chronic diseases percentage. Diabetic diseases prevalence also more occurs in female than in male's old adult (30\% and 28\%) respectively (Information and decision support center, 2008).

The chronic diseases represent a major problem and public health burden in developing countries. It represents $73 \%$ of mortality and $60 \%$ of global morbidity burden. There is emerging evidence that diabetes mellitus, obesity, hypertension and hyperlipidemia contribute to national morbidity \& mortality in Egypt as it represents about 26\% of all deaths related to chronic diseases (Ellabany \& Abd El Nasser, 2006).

Chronic diseases account for $70 \%$ of all deaths in the U.S., which is 1.7 million each year. These diseases also cause major limitations in daily living for almost 1 out of 10 Americans or about 25 million people (Centers for Disease Control and Prevention, 2010). In Egypt, $41 \%$ of all deaths are from chronic disease (WHO, 2004). The prevalence of hypertension and diabetes mellitus in the adult 
population is around $26 \%$ and $9 \%$, respectively. A survey for detection of pre-diabetes in the governorates of Cairo, Menoufia and Sohag found that the prevalence to be $11 \%, 7 \%$ and $18 \%$, respectively (WHO, 2006).

A chronic disease is generally hereditary or is the result of factors such as poor diet and living conditions, using tobacco or other harmful substances, or a sedentary lifestyle. Such a disease is not typically contracted from another person by contagion, because most chronic illnesses are not caused by infection (Holetzky \& Foster, 2010). Also heavy and chronic use of alcohol and use of illicit drugs increase the risk of disease and injuries. Cigarette smoking increases the risk of lung cancer, heart disease, emphysema, and other diseases. Obesity increases the risk of heart disease, diabetes, and stroke (National Center for Health Statistics U.S, 2007).

Managing chronic diseases requires a long-term relationship with the patient and places. Additional demands on the health system, in particular the need to maintain a patient's history and monitor his/her progress. (Fraser et al., 2007). Management of such conditions includes learning to live with symptoms and/or disabilities and coming to terms with identity changes brought about by having a chronic condition. It also consists of carrying out the lifestyle changes and regimens that are designed to keep symptoms under control and to prevent complications (WHO, 2008).

Gerontological nurse gives direct, hands-on care to the older adults in a variety of settings. The nurse as a care provider should be educated about the common disease processes seen in the older population. This includes knowledge of the backgrounds and statistics, risk factors, signs and symptoms, usual medical treatment, nursing care through evidence-based practice, and rehabilitation, if applicable gerontological nurses focus on their teaching on modifiable risk factors. Many diseases of aging can be prevented through lifestyle modifications such as healthy diet, smoking cessation, appropriate weight maintenance, increased physical activity, and stress management. Nurses have the responsibility to educate the older adult population about ways to decrease the risk of certain disorders such as heart disease, cancer, and stroke, the leading causes of death for this group (Kristen et al., 2006).

Intervention in the care of chronically ill individual must take into consideration the client's emotional responses, individual need, motivation for self care, supports from family and friends, and available resources as well as the trajectory experience. Chronic illness affects all aspects of person's life, and interventions must be holistic in focus (Ebersole et al., 2008).

The patient in hospital discharge needed to provide information about any following-up laboratory procedures that might be required after discharge. Provide the dates and times that the patient must receive following-up care with the primary healthcare provider (Sommers et al., 2007). Following-up contacts initiated by agencies receiving a referral for families who need assistance and support enhance the use of those services by the families/caregivers (Kristen et al., 2006).

Significance of the study

Nationally in Egypt, the Health Division of the National Council for Social Services revealed that nearly $43 \%$ of the Egyptians are unable to receive adequate health care. The access to health care is not only restricted to the improved, but includes a high proportion of the middle-class. This results in the government's inability to properly provide health care services to the wide range of people and is unable to give even basic health services to 29 million people (Abd el Salam, 2009).

The incidence of chronic diseases is rising dramatically in the Eastern Mediterranean Region. Currently $45 \%$ of the Region's disease burden is due to non communicable disease (NCD). It is expected that this burden will rise to $60 \%$ by the year 2020 (WHO, 2004).

The incidence of chronic diseases hinders large proportion of Egyptians to enjoy a long, healthy and prosperous life (Rocco et al., 2011). The chronic diseased patient needs regularly checkup, investigation and observes the progress of health status to prevent complication

Aim of the study.

The study aims at

- Identifying the factors affecting the follow up care among elderly patient suffering from chronic diseases at Assiut University Hospital Clinics.

\section{Subjects And Methods:}

Study design: Descriptive research design is used in this study

Study setting:The study carried out at outpatient chronic disease clinics at Assiut University Hospital; it includes (diabetes mellitus, chest, cardiac, cancer, hypertension, hepatitis viruses, and physiotherapy clinics).

Sample:Quta sample was used to collect the data of this study. It consisted of the elderly patients who had the inclusion criteria, who were attending to the previous mentioned setting, the total number of them were 1179 elderly patient suffering from chronic diseases.

Tools of the study: 
Structured Interview Questionnaire sheet was developed by the researchers based on a reviewing of relevant literature to collect the data it consists of three parts:- Part I: Includes items related to socio demographic characteristic of the elderly patient: such as patient name, date, age, sex, residence, educational level, marital status, occupation, income by used socioeconomic scale (Abed El-Twab, 2004).

Part II: Includes items related to present history of chronic illnesses and family history: - Present history of chronic disease includes question about: name of chronic disease, onset of disease, duration of diseases, signs and symptoms, present complain, and degree of independency, complications of chronic diseases, family history of chronic disease and degree the relative between the elderly patient and the affected person in the family.

Part III: - Frequency, places of follow up, investigations and examinations includes: Number of follow up visits for a hospital, name of clinics to follow up Regularity of follow up, causes that disabled patient follow up and type of investigation don for the patient.

\section{Methods:}

\section{I- Preparation phase:}

An official permission is obtained from the Dean of Faculty of Nursing to the director of Assiut University Hospital. To carry out this study, this letter includes the nature and purpose of the study. It is briefly explaines through direct personal communication.

\section{II-Pilot study:}

A pilot study carried out before starting data collection on 20 patients, the aim of pilot study is to assess tools clarity and applicability, time needed for filling in the sheet, moreover. These 20 patients are excluded from the actual sample. The necessary modifications are done according to the result of the pilot study.

\section{III-Data Collection:}

The present study carried out on six months starting from October 2011 to April 2012 at the designated sites cancer clinics, physiotherapy clinics, cardiac clinics, and hypertension clinics- available daily, chest clinics available daily- except on Wednesday, diabetic clinics available on Sunday, Tuesday and Thursday, and hepatitis viruses' clinics are available every day except on Monday. Every day collected about 5 to 15 sheets daily, and the time needed to filling the sheet is approximately 15 to 20 minutes.

IV- Ethical considerations: - Oral consent is taken from each patient who participates in the study. Confidentiality of obtaining information is assured, the purpose and the nature of the study is explained to all participates.
V-Statistical design: The obtained data are reviewed, prepared for computer processing, coded, analyzed, and tabulated. Data entry is done using the SPSS $16 \quad .0$ statistical software package. Data is presented using the descriptive statistics in the form of frequencies and percentages, means, standard deviations and using correlation.

\section{Results:}

Table (1) Percentage distribution of the elderly patients regarding their socio demographic characteristics attending to chronic diseases outpatient clinics at Assiut University Hospitals

\begin{tabular}{|c|c|c|}
\hline $\begin{array}{l}\text { Socioeconomic } \\
\text { characteristics }\end{array}$ & No. $=(1179)$ & $\%$ \\
\hline \multicolumn{3}{|l|}{ Gender } \\
\hline - $\quad$ Male & 550 & 46.6 \\
\hline - $\quad$ Female & 629 & 53.4 \\
\hline \multicolumn{3}{|l|}{ Age (year) } \\
\hline $60-$ & 992 & 84.1 \\
\hline $70-$ & 164 & 13.9 \\
\hline$-\quad 80-<90$ & 23 & 2.0 \\
\hline Mean \pm S.D. & \multicolumn{2}{|c|}{$66.78 \pm 4.32$} \\
\hline \multicolumn{3}{|l|}{ Resident } \\
\hline - $\quad$ Rural & 765 & 64.9 \\
\hline Urban & 414 & 35.1 \\
\hline \multicolumn{3}{|l|}{ Education status } \\
\hline - $\quad$ Illiterate & 960 & 81.4 \\
\hline - $\quad$ Read \& write & 110 & 9.3 \\
\hline - $\quad$ Primary school & 86 & 7.4 \\
\hline $\begin{array}{ll} & \text { Secondary school and } \\
\text { university }\end{array}$ & 23 & 1.9 \\
\hline \multicolumn{3}{|l|}{ Marital status } \\
\hline - $\quad$ Married & 917 & 77.8 \\
\hline - $\quad$ Widow & 262 & 22.2 \\
\hline \multicolumn{3}{|l|}{ Family Size } \\
\hline - $\quad 1$ to 3 person & 179 & 15.2 \\
\hline - $\quad 4$ to 6 person & 736 & 62.4 \\
\hline - 7 person or more & 264 & 22.3 \\
\hline \multicolumn{3}{|l|}{ Occupation } \\
\hline - $\quad$ Housewife & 569 & 48.2 \\
\hline - $\quad$ Farmer & 405 & 34.4 \\
\hline - $\quad$ Retired & 161 & 13.7 \\
\hline $\begin{array}{l}\text { Technical and non } \\
\text { technical }\end{array}$ & 44 & 3.7 \\
\hline \multicolumn{3}{|l|}{$\begin{array}{l}\text { Monthly income group } \\
\text { (pound) }\end{array}$} \\
\hline$-\quad<200$ & 242 & 20.5 \\
\hline$-\quad 200-300$ & 259 & 22.0 \\
\hline$-\quad 300-400$ & 205 & 17.4 \\
\hline$-\quad>400$ & 473 & 40.1 \\
\hline
\end{tabular}


Figure (1): Percentage distribution of elderly patients attending to chronic diseases outpatient clinics at Assiut University Hospitals

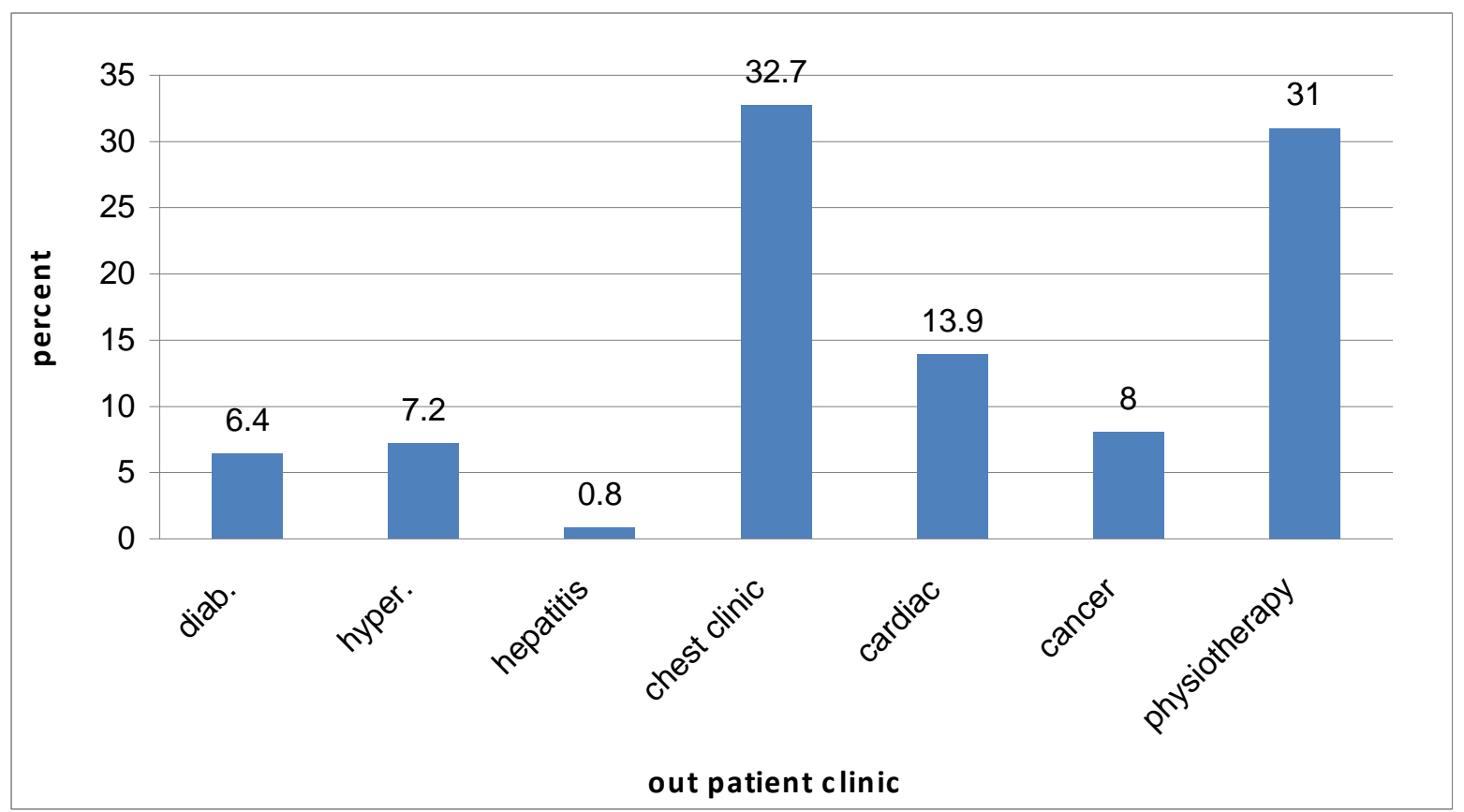

Table (2) Percentage distributions of the elderly patient's regarding the health insurance follow up visits

\begin{tabular}{|l|c|c|}
\hline Health insurance & No.= (1179) & \% \\
\hline Health insurance & & 52 \\
\hline$-\quad$ Yes & 1117 & 94.7 \\
\hline$-\quad$ No & & \\
\hline Benefits of health insurance & 6 & 9.7 \\
\hline$-\quad$ Doing analyses & 6 & 9.7 \\
\hline$-\quad$ Doing routine check up & 27 & 43.5 \\
\hline$-\quad$ Taking a monthly medication & 23 & 37.1 \\
\hline$-\quad$ More than one benefits & & 48.4 \\
\hline Routine follow up care & 30 & 51.6 \\
\hline$-\quad$ Yes & 32 & \\
\hline$-\quad$ No & & 45.1 \\
\hline Frequency of visit to health insurance & 28 & 48.4 \\
\hline$-\quad$ Every month & 30 & 6.5 \\
\hline$-\quad$ Every 3 to 6 months & 4 & \\
\hline$-\quad$ When feeling tired & & \\
\hline
\end{tabular}


Table (3) Percentage distribution of elderly patients regarding their follow up care visits.

\begin{tabular}{|c|c|c|}
\hline Follow up visits & No. $=(1179)$ & $\%$ \\
\hline \multicolumn{3}{|l|}{ Doing follow up visit } \\
\hline$-\quad$ Yes & 1061 & 90.0 \\
\hline$-\quad \mathrm{No}$ & 118 & 10.0 \\
\hline \multicolumn{3}{|l|}{ Onset of follow up } \\
\hline - $\quad$ After the onset of disease & 1041 & 88.3 \\
\hline - $\quad$ After one month of disease onset & 75 & 6.3 \\
\hline - $\quad$ After two months of disease onset & 27 & 2.3 \\
\hline - $\quad$ After 6 months of disease onset & 15 & 1.3 \\
\hline - $\quad$ Other & 21 & 1.8 \\
\hline \multicolumn{3}{|l|}{ Places for follow up } \\
\hline - $\quad$ University Hospital & 980 & 92.4 \\
\hline $\begin{array}{ll} & \text { Central hospital }\end{array}$ & 18 & 1.7 \\
\hline - $\quad$ Rural unit & 27 & 2.5 \\
\hline - $\quad$ Insurance hospital & 15 & 1.4 \\
\hline - $\quad$ Special clinic & 21 & 2.0 \\
\hline - Total & 1061 & 100.0 \\
\hline \multicolumn{3}{|l|}{ Regular to follow up } \\
\hline - Yes & 1118 & 94.8 \\
\hline$-\quad$ No & 61 & 5.2 \\
\hline \multicolumn{3}{|l|}{ Frequency of regular follow up } \\
\hline - Day after day & 110 & 9.9 \\
\hline - $\quad$ Every 15 day & 16 & 1.4 \\
\hline - $\quad$ Every month & 966 & 86.4 \\
\hline - $\quad$ Every 2 and 3 month & 26 & 2.3 \\
\hline \multicolumn{3}{|l|}{ Causes of irregular follow up } \\
\hline - $\quad$ Financial causes & 28 & 45.9 \\
\hline - $\quad$ Long distance of health care service & 10 & 16.4 \\
\hline - $\quad$ Dependant on other person & 23 & 37.7 \\
\hline \multicolumn{3}{|l|}{ Causes that prevents patient to follow up } \\
\hline - $\quad$ Financial causes & 63 & 53.4 \\
\hline - $\quad$ Dependent on other $\&$ there are not available & 32 & 27.1 \\
\hline - $\quad$ Long distance of the place & 23 & 19.5 \\
\hline Total & 118 & 100.0 \\
\hline
\end{tabular}

Table (4) Correlation between elderly patient's socio demographic characteristic and doing follow up visits (No 1179)

\begin{tabular}{|l|l|l|l|l|l|l|}
\hline \multirow{2}{*}{$\begin{array}{c}\text { Socio-demographic } \\
\text { characteristics }\end{array}$} & \multicolumn{2}{|c|}{ Doing follow up visit } & \multicolumn{2}{c|}{ Onset of follow up } & \multicolumn{1}{c|}{$\begin{array}{c}\text { Frequency of regular } \\
\text { follow up }\end{array}$} \\
\cline { 2 - 7 } & \multicolumn{1}{|c|}{$\mathbf{r}$} & \multicolumn{1}{|c|}{$\mathbf{p}$} & $\mathbf{1}$ & \multicolumn{1}{c|}{$\mathbf{p}$} & \multicolumn{1}{c|}{$\mathbf{~}$} & \multicolumn{1}{c|}{ p } \\
\hline Gender & 0.006 & 0.839 & 0.039 & 0.180 & 0.049 & 0.093 \\
\hline Age (year) & 0.013 & 0.655 & 0.006 & 0.846 & 0.050 & 0.086 \\
\hline Resident & 0.039 & 0.182 & -0.009 & 0.758 & 0.089 & $0.002^{* *}$ \\
\hline Educational status & 0.004 & 0.891 & -0.020 & 0.489 & 0.072 & $0.013^{*}$ \\
\hline Marital status & 0.053 & 0.070 & 0.059 & $0.042^{*}$ & 0.042 & 0.151 \\
\hline Family size & 0.035 & 0.233 & -0.015 & 0.610 & -0.016 & 0.585 \\
\hline Occupation & 0.009 & 0.746 & 0.049 & 0.095 & 0.042 & 0.151 \\
\hline $\begin{array}{l}\text { Monthly income } \\
\text { (pound) }\end{array}$ & -0.034 & 0.250 & -0.080 & $0.006 * *$ & 0.004 & 0.883 \\
\hline
\end{tabular}


Table (5) Correlation between elderly patient's socio demographic characteristic and regular follow up and irregular follow up (No 1179).

\begin{tabular}{|c|c|c|c|c|}
\hline \multirow{2}{*}{$\begin{array}{l}\text { Socio-demographic } \\
\text { characteristics }\end{array}$} & \multicolumn{2}{|c|}{ Regular to follow up } & \multicolumn{2}{|c|}{ irregular follow up } \\
\hline & $\mathbf{r}$ & $\mathbf{p}$ & $\mathbf{r}$ & $\bar{p}$ \\
\hline Gender & 0.019 & 0.518 & 0.038 & 0.197 \\
\hline Age (year) & 0.019 & 0.515 & -0.001 & 0.978 \\
\hline Resident & 0.021 & 0.478 & 0.019 & 0.504 \\
\hline Educational status & 0.022 & 0.455 & 0.002 & 0.952 \\
\hline Marital status & 0.087 & $0.003 * *$ & 0.097 & $0.001 * *$ \\
\hline Family size & -0.009 & 0.763 & -0.031 & 0.288 \\
\hline Occupation & -0.004 & 0.903 & 0.017 & 0.565 \\
\hline $\begin{array}{l}\text { Monthly income } \\
\text { (pound) }\end{array}$ & -0.033 & 0.264 & -0.012 & 0.688 \\
\hline
\end{tabular}

Table (6) Correlation between elderly patient's socio demographic characteristic and causes that prevents follows up (No 1179).

\begin{tabular}{|l|c|c|}
\hline \multirow{2}{*}{\multicolumn{1}{|c|}{ Socio-demographic characteristics }} & \multicolumn{2}{|c|}{ Causes that prevents patient to follow up } \\
\cline { 2 - 3 } & $\mathbf{r}$ & $\mathbf{P}$ \\
\hline Gender & 0.013 & 0.652 \\
\hline Age (year) & 0.005 & 0.867 \\
\hline Resident & 0.019 & 0.508 \\
\hline Education status & 0.005 & 0.867 \\
\hline Marital status & 0.035 & 0.234 \\
\hline Family size & 0.036 & 0.220 \\
\hline Occupation & 0.019 & 0.512 \\
\hline Monthly income (pound) & 0.068 & $0.019^{*}$ \\
\hline
\end{tabular}

Table (7) Correlation between elderly patient's chronic disease and routine follow up (No 1179).

\begin{tabular}{|l|c|c|c|c|c|c|}
\hline \multirow{2}{*}{\multicolumn{1}{|c|}{ Routine follow-up }} & \multicolumn{2}{c|}{$\begin{array}{c}\text { Types of chronic } \\
\text { diseases }\end{array}$} & \multicolumn{2}{c|}{ Onset of disease } & \multicolumn{2}{c|}{$\begin{array}{c}\text { Degree of } \\
\text { independent }\end{array}$} \\
\cline { 2 - 7 } & $\mathbf{r}$ & $\mathbf{p}$ & $\mathbf{r}$ & $\mathbf{p}$ & $\mathbf{r}$ & $\mathbf{p}$ \\
\hline Doing follow up visit & 0.042 & 0.151 & 0.025 & 0.395 & -0.063 & $0.031^{*}$ \\
\hline Onset of follow up & -0.034 & 0.239 & 0.040 & 0.173 & 0.050 & 0.087 \\
\hline Places for follow up & 0.076 & $0.009^{* *}$ & 0.051 & 0.079 & -0.045 & 0.126 \\
\hline Regular to follow up its now & 0.000 & 0.990 & 0.036 & 0.218 & -0.037 & 0.199 \\
\hline Frequency of regular follow up & 0.153 & $0.000^{* *}$ & -0.079 & $0.007 * *$ & 0.003 & 0.920 \\
\hline $\begin{array}{l}\text { Causes of irregular } \\
\text { follow up }\end{array}$ & 0.016 & 0.591 & 0.000 & 0.988 & -0.004 & 0.904 \\
\hline $\begin{array}{l}\text { Causes of visiting the University } \\
\text { Hospital }\end{array}$ & 0.071 & $0.014^{*}$ & 0.022 & 0.454 & -0.075 & $0.010^{*}$ \\
\hline $\begin{array}{l}\text { Causes that prevents patient to follow } \\
\text { up }\end{array}$ & -0.028 & 0.336 & -0.039 & 0.179 & 0.060 & $0.039^{*}$ \\
\hline $\begin{array}{l}\text { Frequency of follow up visits at last } 6 \\
\text { month }\end{array}$ & 0.229 & $0.000^{* *}$ & -0.021 & 0.478 & 0.001 & 0.974 \\
\hline
\end{tabular}


Table (1) illustrates the distribution of the studied sample regarding their socioeconomic characteristics, it is found that more than half of the studied sample $(53.4 \%)$ are females , $(84.1 \%)$ are their ages are between $60-<70$ years, the age mean \pm S.D. was (66.78 44.32$)$. Approximately more than three quarters of them $(77.8 \%)$ are married about two thirds of them $(64.9 \%)$ live in rural area, and the majority of them $(81.4 \%)$ are illiterate.

As regards to the occupation of the studied sample, it is observed that $(48.2 \%)$ are housewives, and two fifth of the study sample $(40.1 \%)$ the income $(>400$ pounds) monthly.

Figure (1) represents the distribution of the chronic diseases among elderly patients it was clear that about one third of the sample $(32.7 \%)$ are elderly patients complain from chest disease followed by $(31.0 \%)$ of them complain from neurological and orthopedic disease, visiting physiotherapy clinics and only $(0.8 \%)$ of the patients complain from hepatitis disease.

Table (2) distributes of the elderly patients regarding their health insurance this table represents that $(94.7$ $\%$ ) of the study sample don't have health insurance. Concerning the benefits from health insurance it is observed that $(43.5 \%)$ of the elderly are take a monthly medication, and $(9.7 \%)$ of them make analyses and the same percentage make routine checkup. Concerning the doing routine follow up $(51.6 \%)$ don't follow up while $(48.4 \%)$ do routine follow up, and nearly half of the elderly patient (48.4\%) visit health insurance hospitals every 3 and 6 months.

As regarding to the distribution of the study sample about their follow up, table (3) shows that (90.0\%) did follow up visit while $(10.0 \%)$ don't follow up visit. Concerning the onsets of follow up (88.3\%) do after the onset of disease and the majority of the study sample (92.4\%) do follow up at University Hospital.

Most of the study elderly patients $(94.8 \%)$ were do regular follow up, and $(86.4 \%)$ did follow up every month. As regarding the reasons of irregular follow up $(45.9 \%)$ due to financial causes, while $(37.7 \%)$ depend on other person, and $(16.4 \%)$ have long distance of health care service, while the reasons that prevent follow up $(53.3 \%)$ are due to financial causes and $(1.9 \%)$ have long distant of the place.

Table (4) displays the correlation between elderly patient's socio demographic characteristic and follow up, onset of follow up and frequency of regular follow up. There is negative correlations statistically significant is found between onset of follow up, making follow up visit and elderly patients' income $\left(\mathrm{r}=-0.080 \& \mathrm{p}=0.006^{* *}\right)(\mathrm{r}=-0.034 \& \mathrm{p}=0.250)$ respectively, while the positive correlations and statistically significant was found between onset of follow up and marital status $\left(r=0.059 \& \mathrm{p}=0.042^{*}\right)$, finally there is apositive correlation and statistically significant between frequency of regular follow up and resident, educational status $(\mathrm{r}=0.089 \& \mathrm{p}=$ $0.002 * *, r=0.072 \& \mathrm{p}=0.013 *$ ) respectively.

Correlation between elderly patients' socio demographic characteristic and regular follow up and reasons of irregular follow up in table (5) reveals that the positive correlation and statistically significant between regular of follow up and marital status ( $\mathrm{r}=$ $0.087 \& \mathrm{p}=0.003 * *)$ and between reasons of irregular follow up and marital status $(r=0.097 \& p=$ $0.001 * *)$.

Table (6) displays the correlation between elderly patient's socio demographic characteristic and causes that preventing follows up. It was found that positive correlation and statistically significant were found between elderly patient income and causes that prevents follows up $(r=0.068 \& \mathrm{p}=0.019 *)$.

Correlation between the elderly patient's chronic disease and the routine follow up. Table (7) reveals that positive correlation and statistically significant is found between elderly patients types of chronic diseases and places of follow up, frequency of regular follow up, causes of visiting the University Hospital and frequency of follow up visits at the last 6 months $\left(\mathrm{r}=0.076 \& \mathrm{P}=0.009^{*} *, \mathrm{r}=0.153 \& \mathrm{p}=0.000^{* *}, \mathrm{r}=\right.$ $\left.0.071 \& \mathrm{p}=0.014 *, \mathrm{r}=0.229 \& \mathrm{p}=0.000^{* *}\right)$ respectively, also positive correlations and statistically significant is found between the elderly patients onset of disease and frequency of regular follow up ( $\mathrm{r}=-0.079 * * \& \mathrm{p}=0.007 * *)$, also the table shows that there is positive correlation between the degree of independent and causes that prevent patient from the follow up $\left(\mathrm{r}=0.060 \& \mathrm{p}=0.039^{*}\right)$.

\section{Discussion:}

The need of the health care increases with age - four times as many people aged 85 years old and over need daily care compared to those aged 65-74 years (Botsis \& Hartvigsen, 2008). With the increase in age, people lose their creativity, problem-solving ability, learning skills and develop short-term memory loss. It is important for an elderly person to have a frequent doctor visits (Sanjel et al., 2012).

Regarding the socio demographic characteristic of the study sample such as gender, more than half of them $(53.4 \%)$ are female's. In this study there is a statistically significant relation ship is found between onset of disease and elderly patient's gender $(\mathrm{r}=0.066$ $\& \mathrm{p}=0.024)$. Female elderly who live longer have more chance to have illness thus female elderly have to receive health services more than male elderly. This finding is agreed with Netithanakul \& 
Soonthorndhada (2009) which reported that oldest elderly include more females than males. Hagedoorn et al (2001) reported that women may be more strongly affected by the health condition of their spouse than men.

As regard to the age old in the present study, the majority of the sample $(84.1 \%)$ aged between $60-<70$ years and $(13.9 \%)$ of them her are aged $70-<80$ years old. This finding is agree with Center for Technology and Aging (2011) which reported that the prevalence of multiple chronic conditions is particularly high among older adults with over $80 \%$ of people are over the age of 65 have years old more than one condition.

Concerning the residents in the present study, about more than half of the study sample live in rural area and the rest of them live in urban area. This study is positive correlation and statistical significant is found between types of chronic diseases and elderly patient's resident $(r=0.060 \& p=0.038)$, while many health services are lack in rural area due to the difficult of transportations, poverty, and lack of awareness of health resources in rural than urban area. It is agrees with Moulton et al (2005) who reported that rural elderly patients are not only more likely to suffer from poor health, but they also tend to have less income and less education when compared to urban elderly patients. Also in the same line with (Hutchison et al., 2010) who stated that: rural elderly patients are also more likely to have chronic conditions such as arthritis, hypertension, diabetes and heart disease.

Regarding to the education level, in the present study, the majority of elderly patients are illiterate, this finding supported by Dalstra et al (2005) \& Moulton et al (2005) they reported that the most chronic diseases show higher prevalence among the lower education group. Concerning the marital status, more than three quarters of the elderly patient are married, and less than one quarter of them are widows. Increasing number of chronic diseases among married older adult due to the life style and they don't concern with health due to the need of their family and focus to meet their needs, this finding is not agreement with Pienta (2000) who reported that marriage also reduces the risk of morbidity. Overall married men and married women are less likely to report they are in poor health; also this finding is in agreement with Sanjel et al (2012) who reported that widowed elderly patients visited more health services than the married and unmarried patients.

Regarding to the monthly income by pound, the present study shows positive correlation and statistical significant are found between types of chronic diseases and elderly patient's income $(r=$
$0.154 \& \mathrm{p}=0.000)$. The patient with chronic disease needs special food, medication and health care services leads to the elderly patients need to more money to pay food and medication and to meet their needs. Also the present studies agree with Schneider (2010) who reported that poverty can't buy medication and nutritious food.

As regarding to the distribution of chronic diseases among elderly patients, it is clear that about one third of the sample were elderly patients complaining from chest disease, while less than one fifth of them complain from cardiac diseases, and $(7.2 \%, 6.4 \%)$ of them were complain from hypertension and diabetes respectively. This finding agreement with Urdinola et al (2008) who reported that respiratory illnesses are the most common disease in Nicaragua: about 59 percent of elderly patients suffered from respiratory illnesses. The present study disagrees with W H O (2006); Information and decision support center (2008) they reported that more common chronic disease in Egypt are cardiovascular diseases.

The finding of the present study shows that vast majority of the elderly patients don't have health insurance while only $(5.3 \%)$ of them have health insurance, elderly patient suffer from chronic diseases are not governmental employ and health insurance provide to employ person and retire person, this finding agreement with Fitzpatrick et al (2004) who reported that the narrow coverage of the existing insurance programs, which only cover approximately $60 \%$ of elderly persons live in urban areas and less than $10 \%$ of them live in rural areas, is a serious barrier for elderly persons need access to health care As regarding to the elderly benefits of the health insurance, it is found that more than two fifth of the sample use health insurance to take the monthly medication, while more than one third of them enumerate more than one benefit such as (doing analyses \& take a monthly medication). Finally $(9.7 \%)$ of them use health insurance for analyses and doing routine checkup, the elderly patient go to hospital insurance to take medication because medication in hospital insurance due to the costs. Jeffrey et al (2009) reported that Long-term care insurance is designed to cover individuals' need of health care outside the hospital, including diagnostics testing, rehabilitation, and custodial care, also Moulton et al., (2005) found that $49 \%$ of the American Indian/Alaska Natives have private insurance coverage.

According to the elderly patients doing routine follow up care, it is estimated that more than half of the sample don't follow up and less than half of them do routine follow up care. It may be elderly patient don't follow up in hospital insurance due to the low health serves, overcrowding, some types of 
medications are not available and the difficult of the hospital routine. Also the present study shows that, less than half of the elderly patient visit health insurance every month or from 3 to 6 months, and only $(6.5 \%)$ visit health insurance when feeling tired. Concerning follow up visits, the vast majority of study sample do regular follow up, also the positive correlation and statistically significant between the regular of follow up and marital status and negative correlation and statistically significant between regular of follow up and the family size, occupation and income. It may attributed by the elderly person with chronic disease need to regularly checkup, investigation, and observe progression of health status to prevent complications, this finding agrees with Vilke et al (2002) who reported the overall $70 \%$ of the patients in USA reported receive follow-up medical care. As regards the time of start the follow up it was found that the majority of studied elderly patients start the follow up after the onset of disease and the minority of them start follow up after one, two or three month of disease onset.

As regarding to the frequency of regular follow up, the majority of the sample do follow up every month, while $(9.9 \%)$ day after day, $(2.3 \%)$ every 2 to 3 month and only (1.4\%) every 15 day. Concerning causes of irregular follow up, less than half of the samples $(45.9 \%)$ are due to financial causes, while more than one third of them $(37.7 \%)$ depend on other person and only (16.4\%) have long distance to allow health care service.

the present study shows that positive correlation and statistically significant is found between elderly patients types of chronic diseases and frequency of follow up visits at last 6 month $(r=0.229 \& p=0.000$ ), and negative correlation and statistically significant between elderly patients onset of disease and frequency of follow up visits at last 6 month $(\mathrm{r}=$ $0.021 \& \mathrm{p}=0.478)$.

Concerning the causes that prevent follow up, about more than half of the sample are due to financial causes, while less than one third of them depend on others and there are not available and only (19.5\%) live far from the place. The present study show positive correlation and statistically significant is found between elderly patient income and causes that prevents follows up $(\mathrm{r}=0.068 \& \mathrm{p}=0.019)$. Elderly patient live in rural area and the transportations are expensive, and there is enough health care services that important causes of prevent follow up, this finding agrees with Schneider (2010) who reported that poverty - can't buy medication, nutritious food. Also it agrees with Shi \& Stevens (2005); Trotochaud (2006) that they reported poverty is the most significant barrier that hinders the elderly population's access to health care, also it is agree with Leight (2003); National Association of Community Health Centers (2011) they reported the barriers to the access of health care are slowly rising among the rural population due to the longer distances to the closest healthcare facility and limitations in transportation. Moulton et al (2005) reported that poverty is the most significant barrier that hinders the elderly population's access to health care.

Conclusions and recommendation

According to the results of the present study, it can be concluded that:

About one third of the elderly patients attended chest clinics followed by physiotherapy clinics, While only $6.4 \%$ of them attended diabetic clinics, More than two third of them are partially independent, also the vast majority of the study sample don't have health insurance, While they do regular follow up at the University Hospital. The results obtained from this study revealed that the ability of older adults to access health care is negatively affected by family income, disability and transportation services.

Consequently and in the light of the present study results, the follow recommendations are suggested:

1. Health insurance must be available for all elderly people over 60 years old who live in rural and urban areas.

2. Regular check-ups at fixed healthcare institutions and receiving health information from health team are important measures to increase chronic disease knowledge among rural elderly patient with chronic diseases.

3. Increasing the elderly people awareness about the importance of follow up and periodic check up to detect early health deviation, to make early management and to prevent complication.

4. Elderly patient people and their family should be acquainted with the various follow up services available in the community to help elderly patient meet their needs.

5. Utilizing the mass media to enhance the awareness of the public of the chronic disease, stressing the importance of its prevention and control.

6. Nurses who are certified in gerontology have special knowledge of the acute and chronic changes specific to the older patient. 


\section{References:}

1. Abd el Salam, M. (2009): Egypt: 29 million don't have proper access to food and health treatment: Egypt, Health News. http://bikyamasr.com/wordpress/? Pp. 6476.

2. Abed el Twab (2004): Socioeconomic scale to assess socioeconomic status of the family: Faculty of Education, Assiut University.

3. Botsis, T., \& Hartvigsen, G. (2008): Current status and future perspectives in telecare for elderly people suffering from chronic diseases: Journal of Telemedicine and Telecare Vol. 14: No 4 Pp 195-203.

4. Center for Technology and Aging, (2011): Health technologies: Applications to benefit older adults, chronic disease management. Www. Teaching aging. otg $/ \mathrm{m}$ Health Position paper Discussion-Draft.pdf.

5. Centers for Disease Control and Prevention, (2010): National Center for Chronic Disease Prevention and Health Promotion, Healthy aging improving and extending quality of life among older Americans. http://www.cdc.gov/aging.

6. Dalstra ,J ., Kunst ,E., Borrell, C ., Breeze, E., Cambois, E., Costa, G., Geurts, J., Lahelma ,E., Van Oyen, H., Rasmussen ,K., Regidor ,E., Spadea ,T., \& Mackenbach ,P. (2005): Socioeconomic differences in the prevalence of common chronic diseases: an overview of eight European countries Int. Journal of Epidemiology. Vol. 34: No (2): Pp 316-326.

7. Ebersole, P., Hess, P., Touny, T., Jett, K., \& Loggen, A. (2008): Toward healthy aging: Human need and nursing response, seventh edition, chapter 10 chronic disease in late life, by Mosby: Pp222:267.

8. Eliopoulos, C. (2010): Gerontological nursing: $7^{\text {th }}$ edition, chapter 1 the aging population. China. Pp 3:12.

9. Ellabany, E., \& Abd El Nasser, A. (2006): Ministry of health \& population, Egypt preventive sector central Epidemiology and Disease Surveillance (ESU) Non-Communicable Disease Surveillance Unit (NCDSU) community based survey study on non-communicable diseases and their risk factors, Egypt. http://www.who.int/chp/steps/STEPS_Report_E gypt_2005-06.pdf

10. Fitzpatrick A., Pow, N., Cooper, L., Lves, D., \& Robbins J. (2004): Health insurance and the elderly. Barriers to health care accesses to the elderly and who perceive them. Journal of Public Health. Vol. 94: No (10), Pp1788-1794.
11. Fraser, H., Allen, C., Bailey, C., Douglas, G., Shin, S., \& Bla, J. (2007): Information systems for patient follow-up and chronic management of HIV and tuberculosis: A life-saving technology in resource-poor Areas, Journal of Med Internet Res; Vol. 9: No (4):Pp29.

12. Hagedoorn, M., Sanderman, R., Ranchor, A., Brilman, E., Kempen, G., \& Ormel, J. (2001): Chronic disease in elderly couples: Are women more responsive to their spouses' health condition than men? Journal of Psychosomatic Research. Vol. 51: No (5).Pp 693- 696.

13. Holetzk, S., \& Foster, N. (2010): What is chronic disease? http://www.wisegeek.com/what-is-chronicdisease.htm

14. Hutchison, L., Hawes, C., \& Williams, L. (2010): Access to quality health services in rural area- long term care. Journal of rural health people 2010. Vol. 3.Pp1-19.

15. Information and decision support center, (2008): Characteristic of elderly in Egypt. Information reports. www.idsc.gov.eg

16. Jeffrey, B., Joseph, G., Mary, E., Tudenski, S., Kevin, P., \& Sthana, A. (2009): Hazards' geriatric medicine and gerontology: 6th edition. New York Chicago. Chapter 6 International gerontology. Pp 89

17. Kristen, L., Mauk, D., Crrn, A., \& Aprn, C. (2006) A: Gerontological nursing competencies for care: $1^{\text {st }}$ edition. United States of America. Chapter 1, introduction to gerontological nursing, Pp 6-9.

18. Leight, S. (2003): The application of a vulnerable population's conceptual model to rural health. Journal of Public Health Knurs. Vol. 20: No (6): Pp440-448.

19. Moulton, P., Donald, L., Muus, K., Knudson, A., Wakefield, M., \& Ludtke, R. (2005):

Center for rural health. Prevalence of chronic disease among American Indian and Alaska Native elders. Health connecting resources and knowledge to strengthen the health of people in rural communities. http://ruralhealth.und.edu/projects/nrcnaa/pdf/chr onic_disease1005.pf

20. National Association of Community Health Centers, (2011): Removing barriers to care: Community health centers in rural areas. http://www.nachc.com/client/documents/Rural Fact Sheet.

21. National Center for Chronic Disease Prevention and Health Promotion, (2009): The power of prevention chronic disease, the public health challenge of the $21^{\mathrm{st}}$. http://www.cdc.gov/aging. 
22. National Center for Health Statistics U.S, (2007): Health risk factors of chronic disease. Department of Health and Human Services, centers for disease control and prevention health, United States, with chart book on trends in the health of Americans. http://www.cdc.gov/nchs/data/hus/hus07.

23. Netithanakul, A., \& Soonthorndhada, K. (2009): Equity in health care utilization of the elderly. Journal of Population and Social Studies Vol. 18: No (1).Pp103-122.

24. Pienta, A. (2000): Health consequences of marriage for the retirement years. Journal of Family. Vol. 21: No (5). Pp 559-586.

25. Rocco, L.; Tanabe, K., Suhrcke, M., \& Fumagalli, E. (2011): Policy Research Working. Chronic Diseases and Labor Market Outcomes in Egypt Paper 5575. http://econ.worldbank.org.

26. Sanjel, S., Mudbhari, N., Risal, A., \& Khanal, K. (2012): The utilization of health care services and their determinants among the elderly population of Dhulikhel Municipality Vol.10: No. (1), Pp37.

27. Schneider, C. (2010): Chronic disease: access to health care and barriers to self-management. Community health advisory councils Pp 9-92.

28. Seniors World Chronicle's, (2007): Egypt: 5 million elderly dream of decent life; Digest of International News \& Reports on Aging. http://www.seniorsworldchronicle.com/

29. Shi, L., \& Stevens, G. (2005): Vulnerable Populations in the United States. San Francisco, CA: Jossey-Bass .Journal of Gen Intern Med. Vol. 20: No (2): Pp 148-154.

30. Sommers, M., Johnson, S., \& Beery, T. (2007): Diseases and disorders a nursing therapeutics manual: third edition, United States. Diabetes Mellitus Pp 282- 287, Hepatitis Pp 410- 414. Abdominal Trauma Pp11.

31. Trotochaud, K. (2006): Ethical issues and access to healthcare. Journal of Infus Knurs.; Vol. 29: No (3):Pp165-170.

32. Urdinola, D., Cortez, R., \& Tanabe, K., (2008): Equity, Access to health care services and expenditures on health in Nicaragua 2008. Health, Nutrition and Population (HNP). Discussion paper. The International Bank for Reconstruction and Development /the World Bank1818 H Street, NW Washington, DC 20433.

33. Vilke, GM., Sardar, W., Fisher, R., Dunford, JD., \& Chan, TC.( 2002): Financial and elderly follow up: Follow-up of elderly patients who refuse transport after accessing. Department of emergency medicine, University .Prehosp Emerg Care Vol.6: No (4): Pp391-395.
34. World Health Organization, (2004): Workshop on the WHO STEP wise surveillance system (for Egypt, Sudan and the Republic of Yemen). Regional Office for the Eastern Mediterranean Cairo, Country Presentations Pp 5.

35. World Health Organization, (2006): Guidelines for the prevention, management and care of diabetes mellitus Prevention of diabetes http://apps.who.int/bookorders/WHP/detart1.jsp? sesslan $=1 \& \operatorname{codlan}=1 \& \operatorname{cod} \operatorname{col}=45 \& \operatorname{cod} c \mathrm{ch}=32 \#$.

36. World Health Organization, (2008): Managing chronic conditions. Experience in eight countries on. Behalf of the European observatory on health systems and policies. http://www.euro.who.int/pubrequest Pp23-27

37. World Health Organization, (2011): Chronic diseases. http://www.who.int/topics/chronicdiseases/en/ 